\title{
The European Union post COVID-19: Preserving innovation's cutting edge and fostering social cohesion
}

\section{MARCO BUTI ${ }^{1,2}$ and ISTVÁN P. SZÉKELY ${ }^{3,4 *}$ (1)}

${ }^{1}$ Chief of Staff of the Commissioner for the Economy, European Commission, Brussels, Belgium

${ }^{2}$ LUISS School of European Political Economy, Rome, Italy

${ }^{3}$ Directorate-General for Economic and Financial Affairs, European Commission, Rue de la Loi 170/

Wetstraat 170, 1049, Bruxelles/Brussel, Belgium

${ }^{4}$ Corvinus University of Budapest, Hungary

Received: July 24, 2021 - Revised manuscript received: August 4, 2021 - Accepted: August 15, 2021

(c) 2021 The Author(s)

\begin{abstract}
Despite a long period of post-crisis recovery, the COVID crisis caught the EU in a precarious state. The policy and institutional innovations during the financial crisis tempered the macroeconomic imbalances that had caused the crisis. Nevertheless, the EU was left with a strong trend of divergence in economic and social performance because of the lack of sufficiently strong reforms at EU and national levels. But the lessons of the previous crisis were learned. This time around, the EU-level policy and institutional innovations were decisive. The fiscal capacities of the hard-hit countries were strengthened quickly. Green and digital transformation will require a major new wave of innovation in the corporate sector in the EU. This, in turn, critically hinges on improving the quality of public and private institutions and advancing with the implementation of major reforms at the EU level, such as the digital single market or Capital Market Union. Implementing these reforms fully, and preventing later reversals is a key to stemming the trend of economic and social divergence, thus strengthening the coherence of the EU.
\end{abstract}

\footnotetext{
${ }^{*}$ Corresponding author. E-mail: Istvan-Pal.SZEKELY@ec.europa.eu
}

The views expressed are solely those of the authors and do not necessarily represent the official views of the European Commission. 


\section{KEYWORDS}

COVID-crisis, European Union, Next Generation EU, twin transitions, cohesion

JEL CLASSIFICATION INDICES

E10, F02, 030, Q44, Q56

\section{INTRODUCTION}

A major crisis stress-tests a country, its economy and society. It accelerates some of the pre-existing trends and triggers new ones. It tends to weed out the part of the economy that is not vital any longer and may accelerate the emergence of a new, more modern and productive part (Seiler 2021). It destroys more than necessary if the crisis is not managed well, but it offers a chance for the new parts to emerge faster if the right policy answers are given. These characteristics tend to be more pronounced when a crisis hits soon after the previous one, as the COVID-19 crisis did. It hit the European economy less than a decade after the previous financial and sovereign debt crisis ended.

The process of creative destruction is typically described in the literature as a process in the corporate sector, which can be supported and mitigated by government policies (Aghion et al. 2021). However, creative destruction takes place also in the public sector. A crisis reveals the weaknesses of the existing system and helps the emergence of new functions and institutions that are vital for a society to move forward. More than that, a crisis creates a special environment by putting strong pressure on the political system. In healthy societies, this forces the political system to focus on policy and institutional innovation in the public sector.

This is particularly true for the federal or quasi-federal structures, such as the European Union (EU). They tend to be younger than the nation states and still evolving. The US Social Security emerged as a response to the Great Depression, which made the consequences of having no social security system painfully clear. At that time, it was a major policy and institutional innovation at the federal level that significantly expanded the role and size of the federal state in the US. By now, it is an integral part of the federal state, amounting to more than a quarter of total federal primary expenditure before the COVID-crisis, which enjoys very strong public support.

The history of the EU can also be described as a series of policy and institutional innovations, a large part of which took place as a response to the crises. In the 1950s, the predecessor of the EU was born out of an elemental desire to preserve peace in Europe by eliminating the political and economic roots of wars, the ultimate and most destructive form of crisis. However, these policy and institutional innovations have faced a "political integration trilemma" (Buti 2020). Europe cannot achieve at the same time deep political integration, strong democratic legitimacy, and decision making essentially based on national institutions (Fig. 1). In the 1980s and 1990s, in response to 'Euro-sclerosis', the Single Market and EMU were created. That is, sovereignty was shared at the supranational level by strengthening or creating new European institutions, most notably the European Central Bank (ECB).

The Great Recession and the European Sovereign Crisis revealed several major design problems of the EMU. It also brought about significant policy and institutional innovations, albeit with a considerable delay that made the crisis bigger and longer-lasting than necessary. Moreover, the social cost of the crisis was allowed to be high and unevenly distributed in the countries that were hit hard. 


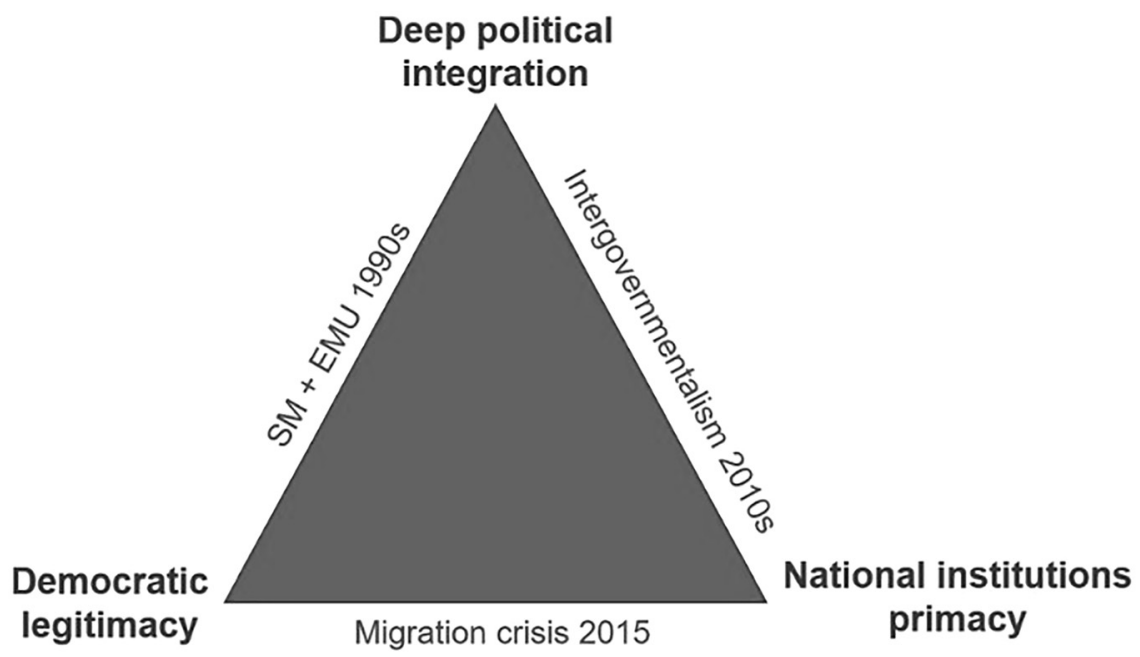

Fig. 1. The political integration trilemma

Source: Buti (2020).

In this crisis, the intergovernmental approach prevailed. In setting up the EFSF (later transformed into the European Stability Mechanism, ESM) and adopting the Fiscal Compact, the European Council rather than Community institutions played the leading role. Whilst the Single Supervisory Mechanism of the Banking Union was established under Community law, the financial support of the Single Resolution Mechanism and the still-to-be-established European Deposit Insurance Scheme (EDIS) were negotiated essentially as intergovernmental tools. Lack of trust and the crystallisation of the division between 'creditors' and 'debtors' underpinned the intergovernmental approach. Moreover, in the absence of sufficient progress with deep reforms, these policy and institutional innovations mostly transformed previous macroeconomic imbalances into divergence in output and investment. That is, nominal imbalances were transformed into real imbalances. Finally, mostly national approaches prevailed during the immigration crisis of the mid-2010s where, under the impulse of the Commission, some common actions were undertaken, but no common EU immigration policy emerged.

The COVID-crisis revealed new weaknesses of the private and public sectors. The lessons of the previous crisis have been learned. The policy reaction was decisive and the policy and institutional innovation at the European level took place upfront and it was commensurate to the challenge. However, it remains to be seen whether these new policies will be fully implemented and sufficient to ensure prosperity and coherence in the Union in the longer run.

As this brief overview of the history of the European crisis response shows, for policy and institutional innovations to come about at the European level and for such reforms to take the $\mathrm{EU}$ in the right direction in a lasting manner, trust, good design, and consistent implementation are essential. Trust between citizens and their respective national governments and the European institutions, and trust between the national governments of the EU and between national and European institutions. The nature of the COVID crisis, the fact that the cause was a pandemic that had originated far away and hit all member states (MSs) of the EU, and that 
human lives were at stake, probably helped with maintaining trust among the MSs and vis-à-vis the European institutions. ${ }^{1}$

\section{THE DEVELOPMENT OF THE EU: FROM THE GOLDEN AGE TO THE "HIGH-INCOME TRAP"}

Until the second oil crisis in the late 1970s, European integration brought about a rapid convergence of the EU MSs to the frontier of economic and social development, matched with a trend of strengthening coherence within the Union. By the time of the first enlargement of the EU in 1973, a large part of the Union had an income level higher in purchasing power than that of the UK that emerged from WWII with a much higher income level than the continental European countries. Despite all the problems of the time, peace, prosperity, and cohesion characterized this period of the Union's history.

The EU countries became the powerhouses of international trade and were among the major global innovator countries. Italy was one of the fastest converging high-middle income countries in the world, rapidly catching up with Germany, France and the UK in terms of income, international trade and innovation. Northern Italy maintained the income level of the richest regions in the EU, such as Baden-Württemberg or Bavaria.

However, developments since then have nuanced this story and the mobilizing force of the original narrative has somewhat faded. Since the mid-1980s, the EU as a whole has been caught up in what we can call the "high-income trap" as its average per capita GDP (in purchasing power parity) has been hovering at around 70 per cent of the income level of the US (Fig. 2). Japan followed a similar pattern with somewhat different timing and ended up in the same landing zone after its lost decade. Up until the financial crisis of 2008-2009, the gradual erosion in the relative income level of the Southern European MSs was counterbalanced by the rapid convergence of the Central and Eastern European (CEE) MSs (EU11) which started at around the turn of the century when the EU membership became a political reality (Székely - Kuenzel 2021).

In this period, the EU was enlarged in several waves and went through major rounds of policy and institutional innovations. As a result, the single market for goods and the introduction of the euro gave a boost to trade, FDI and cross-border finance. The trade, investment and finance channels of the EU worked well, unleashing market forces and allowing firms that were fit for riding these waves to create GVCs and rearrange their production networks to make them globally competitive. However, the institutional channel did not work well: institutional quality in the Southern Europe declined, and after an initial boost in the pre-membership period, it broadly stagnated in the EU11 group until recently (Székely - Kuenzel 2021).

Globally, this period is characterized by the rapid growth of the Asian economy. The transatlantic benchmark was supplemented by a new one. China emerged as a global player and a dominant destination for the low-value-added parts of the global value chains. It had a major impact also on Europe, albeit the EU11 countries offered a highly competitive alternative to Asia, because the EU membership not only brought about unfettered access to the EU's single market, but also legal and institutional protection to foreign investors that China or other Asian countries could not match.

\footnotetext{
${ }^{1}$ However, the impact of a pandemic on the trust of citizens in their governments is likely to be a more complex issue, see Aksoy et al. (2020).
} 


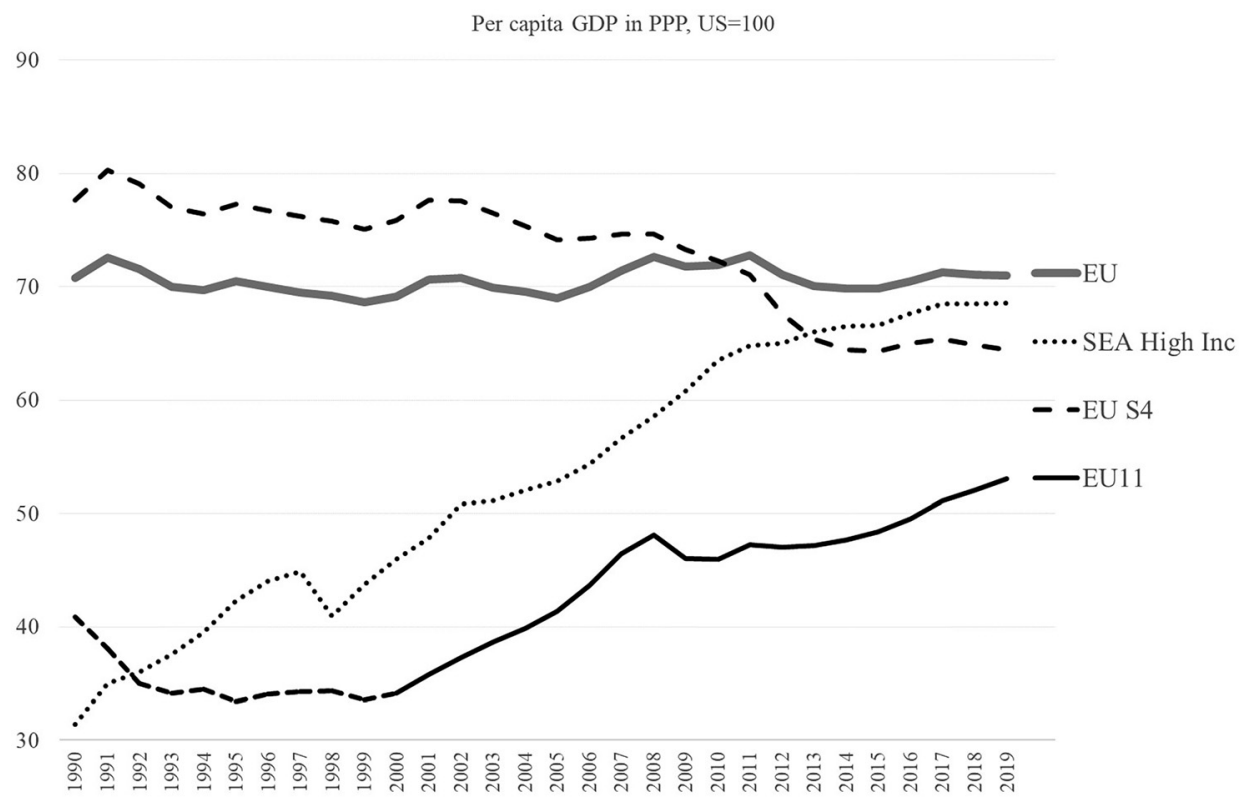

Fig. 2. Per capita GDP of the EU, the Southern and CEE EU members, and high-income countries in South East Asia relative to the US in PPP, 1990-2019

Source: Calculations based on World Bank, World Development Indicators.

Notes: EU S4 includes Greece, Italy, Portugal and Spain. The group of EU11 includes 11 CEE countries that joined the EU since 2004. The group of high-income economies in South East Asia (SEA) includes Hong Kong, Korea, RP, Malaysia, Singapore and Taiwan.

\section{THE LEGACY OF THE GREAT RECESSION AND THE EUROPEAN SOVEREIGN CRISIS}

The previous crisis revealed some fundamental weaknesses of the EU's institutional setup. As a response to the crisis, a major wave of institutional and policy innovation took place in the EU (Lane 2021). Most importantly, it advanced financial market integration (Banking and the Capital Market Unions) and created financial crisis management tools (ESM). Regarding macroeconomic policies, it led to a fundamental change in the approach to monetary policy in the euro area and to a somewhat more relaxed and pragmatic interpretation of the SGP. Concerning structural reforms, it strengthened country surveillance at the European level with the introduction of the European Semester and the Macroeconomic Imbalance Procedure.

\subsection{The trend of divergence}

However, the implementation was uneven. The introduced reforms strengthened the capital base and prudential soundness of the banking system and eliminated macroeconomic (nominal) imbalances within the EU. Nevertheless, despite the strong expansion that followed the previous crisis in the EU as a whole, a trend of major divergence emerged in the economic and social 


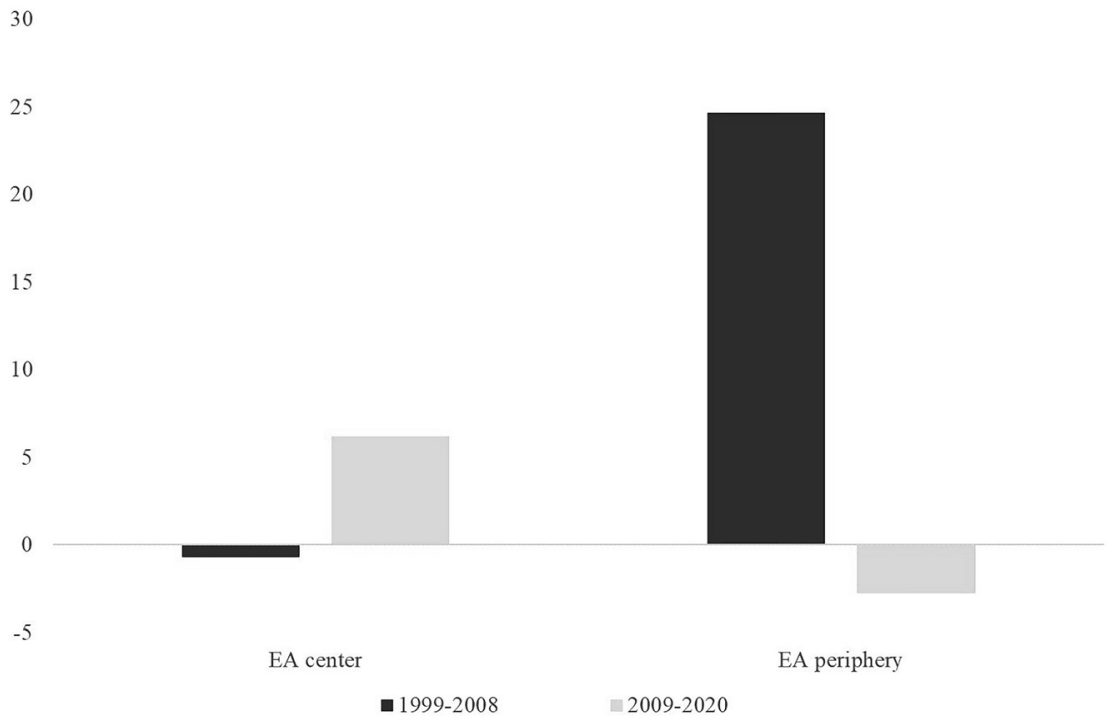

Fig. 3. Cumulative growth rate of non-tradable over tradable value added, and construction over total value added in the euro area, 1995-2020

Source: Based on Buti - Turrini (2015) and AMECO data.

Notes: Weighted average for area core versus euro area periphery, averages for sub-periods: first EMU decade, post-crisis.

performance of the EU MSs. As an outcome, nominal imbalances were transformed into real ones (Buti - Székely 2021). A slow and only partial reversal of the previous trend of excessive allocation of production resources to non-tradable sectors is to a large extent responsible for this negative trend (Fig. 3).

For the first time in the past half-century, the Southern European EU MSs as a group had a lower investment ratio than the EU as a whole (Fig. 4). The downward shift took place in a synchronized fashion, reflecting a concerted effort to make the system of financial intermediation, particularly banks, more resilient in Europe. This curtailed the capital flow to the region via bank lending, suggesting an apparent conflict between two major policy goals, resilience and growth.

To some extent, the decline in total investment in the Southern European EU countries is attributable to fiscal pressures during the crisis. However, the decline in total investment is much larger than the decline in public investment since the previous crisis (Fig. 5).

Similarly to total investment, since the previous crisis, the Southern European countries have a lower public investment ratio than the $\mathrm{EU}$ as a whole, which was not the case during the decade before the crisis. The EU's financial support to the EU11 countries is undoubtedly a major factor explaining the sustained high public investment ratio in this region, a kind of support that was much less available to the Southern European MSs during this period. However, before the crisis, the difference between the two regions in this regard was much less pronounced. Moreover, there was little done to restructure budget expenditure to free up resources for public investment in the Southern European countries, albeit fiscal retrenchment was modest. 


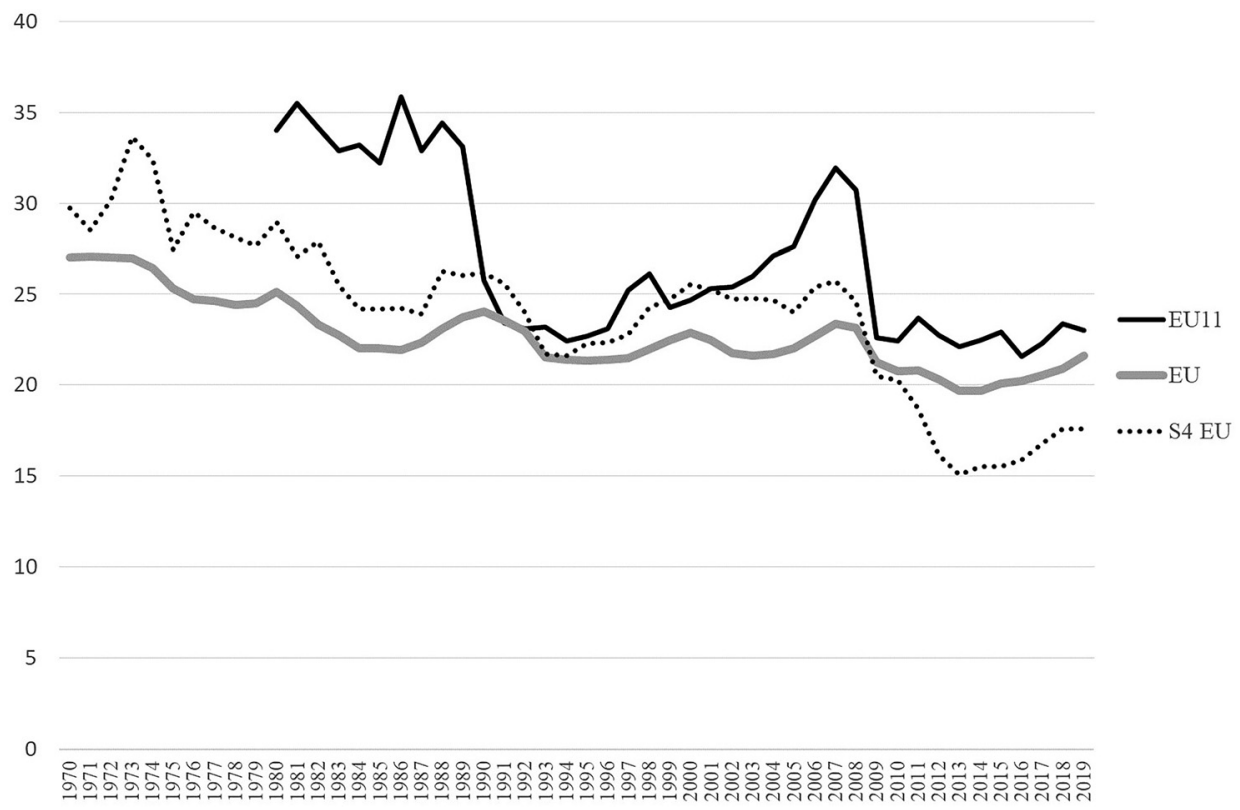

Fig. 4. Investment ratios in the EU, 1970-2019

Source: Own calculations based on World Bank, World Development Indicator database. Notes: Gross-fixed capital formation as a per cent of GDP. For the definition of the country groups EU S4 and EU11 see the Notes to Fig. 2.

The decoupling of Southern Europe from the EU as a whole took place not only among countries but also among regions. Regions that had developed along the same path until the previous crisis, such as the Southern German and Northern Italian regions, some of the most developed parts of the EU, started to deviate significantly, particularly regarding investment trends (Fig. 6).

While the limited fiscal policy space in the Southern European countries is an important factor in this regard, the overall low level of investment is not attributable to this factor alone. In fact, probably this is not the most important factor explaining the decoupling of the region from the EU. Székely - Kuenzel (2021) point to the role of institutional quality in this regard. Their analysis suggests that institutional quality in the Southern European countries continuously deteriorated relative to the rest of the EU in the past two decades. More generally, they show that the EU was not successful in helping its MSs to improve institutions, to learn from those MSs that have the highest quality public and private institutions in the world. While the EU11 countries managed to improve somewhat their institutions, the improvement was rather uneven over time and across countries, most of it taking place before joining the EU.

However, as Fig. 6 suggests, there might have been other forces at work. While the problem with institutional quality started decades ago, the decoupling of Northern Italy from Southern Germany happened only in the past decade, and the sudden deep decline in investment in Northern Italy is hardly attributable to this factor alone. As Fig. 7 shows, it is probably also attributable to a major and sustained decline in private lending. 
6

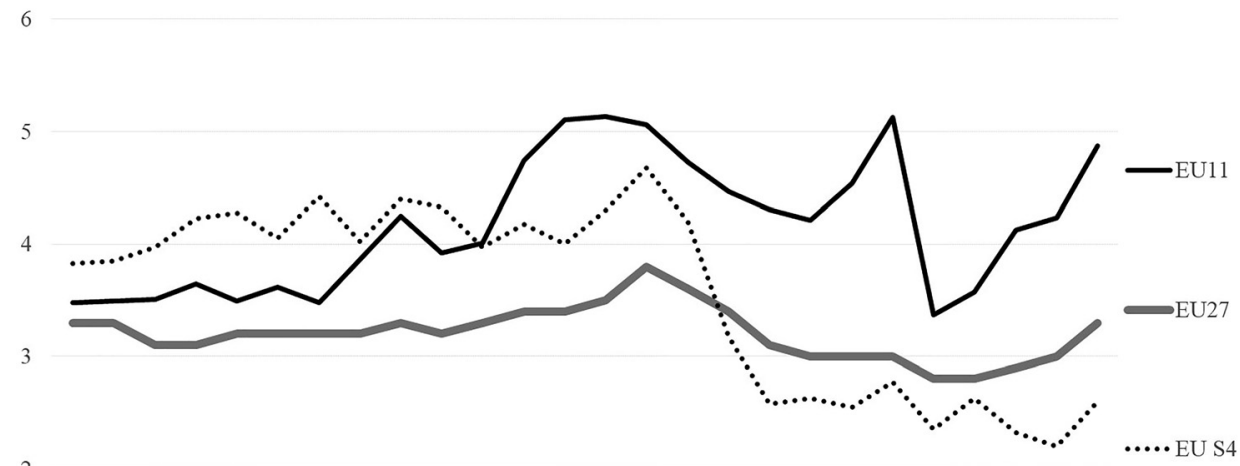

2

1

0

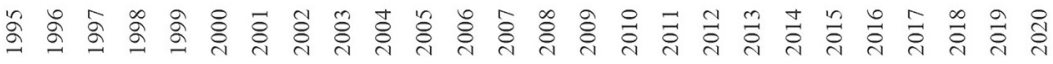

Fig. 5. Public investment ratios in the EU, 1995-2020

Source: Own calculations based on Eurostat's online database.

Notes: Gross fixed capital formation as a per cent of GDP. For the definition of the country groups EU S4 and EU11, see the Notes to Fig. 2.

Part of this adjustment was a desirable correction for the excessive cross-border financial flows that fuelled a real estate bubble in some of the Southern European countries and was to a large extent responsible for the unsustainable current account deficits, also in the EU11 countries (van den Noord - Székely 2011). However, the correction in the Southern European countries, which are all in the euro area, and thus, subject to the much-tightened rules for banks there, is much larger than in the EU11 countries, while the adjustment in the current account follows very similar paths.

Moreover, Italy has sustained large current account surpluses since 2013, that is, in net terms, it has accumulated assets abroad instead of investing at home. Apparently, a deep decline in private investment produced the large current account surplus. Ample domestic savings that in the past were channelled by the domestic banking system into the corporate sector is now channelled abroad. There was no matching sudden decline in institutional quality during this period.

In general, one can argue that, with higher allocative efficiency and more efficient use of investment funds in the private sector, the growth potential is not necessarily reduced if the investment ratio is lower. However, when an economy needs to go through a major transition, such as the twin transition, new investment is critical to introducing the new technology necessary to turn green and digital. Hence, it is essential for the Southern European countries to find a way to boost private investment. 


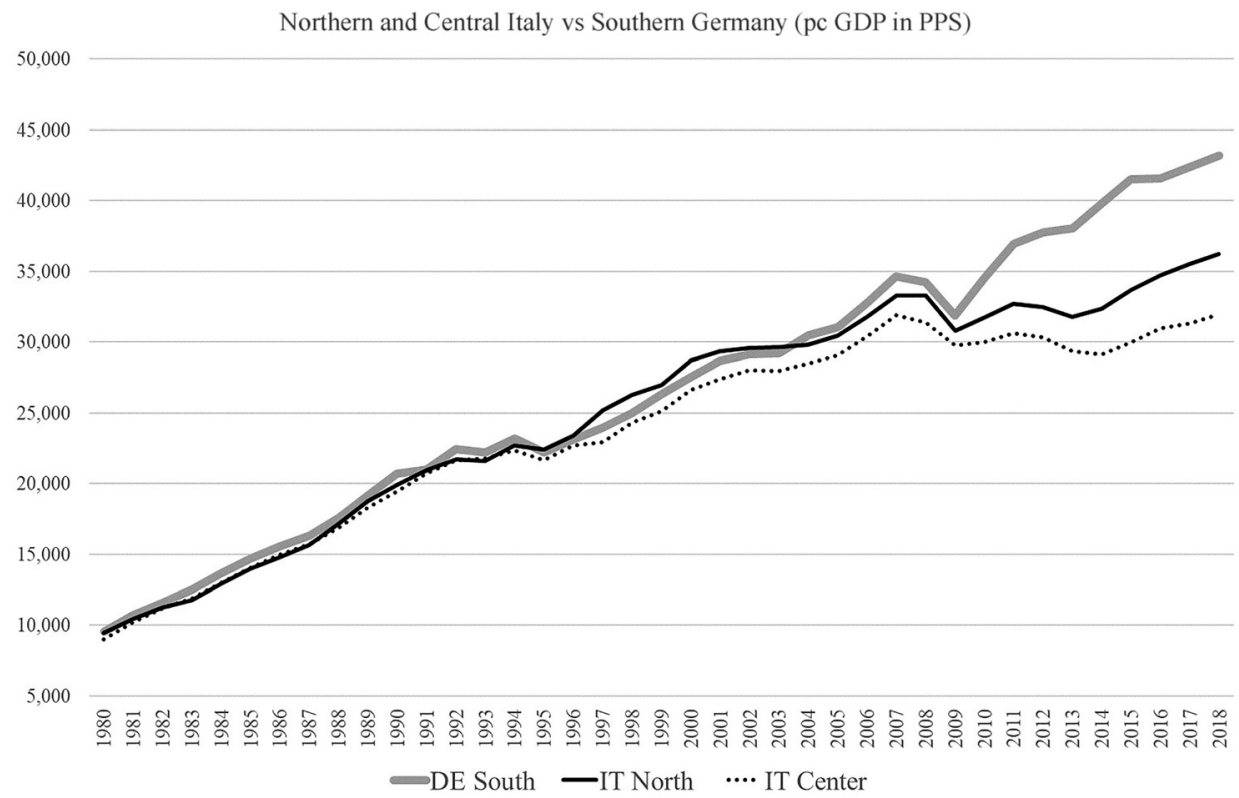

Per capita total investment, real

11,000

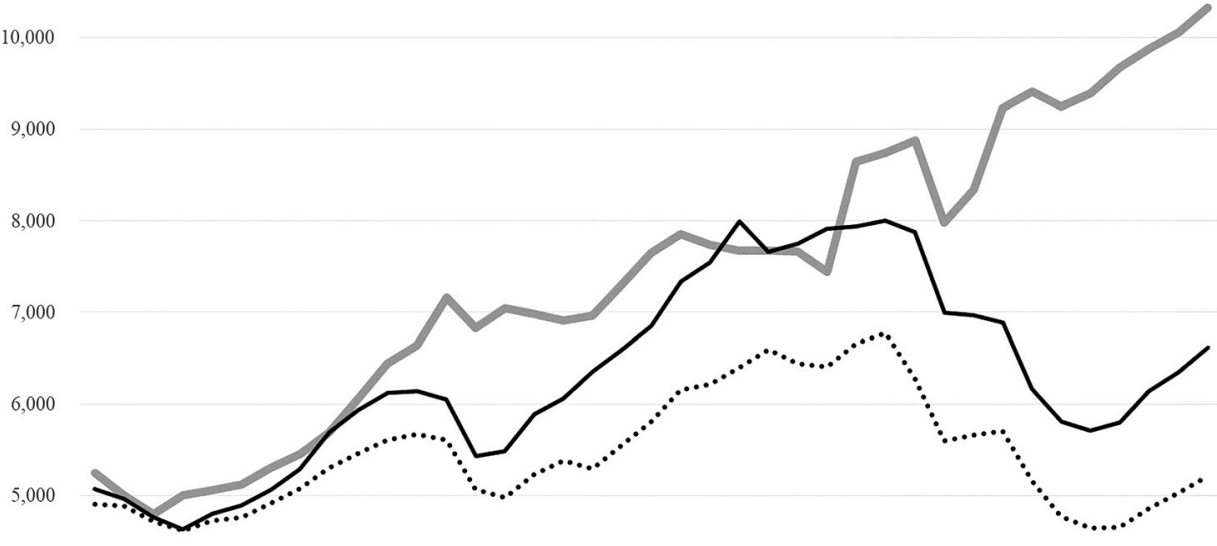

4,000

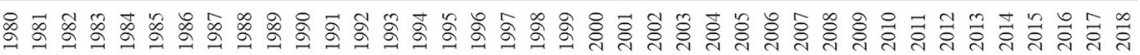
$\longrightarrow$ DE South —IT North …IT Center

Fig. 6. The development of Southern Germany and Northern and Central Italy, 1980-2018 Source: European Commission, ARDECO Online Database, February 2020 release.

Notes: Germany (DE) South includes Baden-Württemberg and Bavaria, Italy (IT) North includes NUTS1 regions of North East and North South. IT Centre includes the NUTS1 regions of Centre. 
Current account balance (\% of GDP)

10

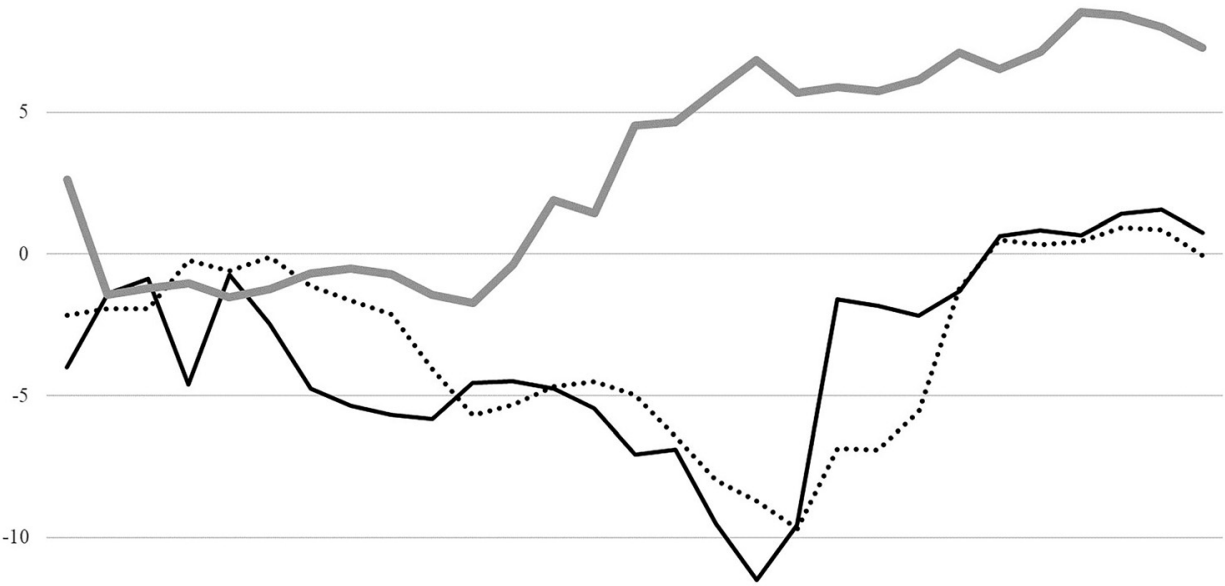

$-15$

19901991199219931994199519961997199819992000200120022003200420052006200720082009201020112012201320142015201620172018 —EU11 $\quad \cdots . .$. EU S4 Germany

Domestic credit to private sector by banks ( $\%$ of GDP)

150

125

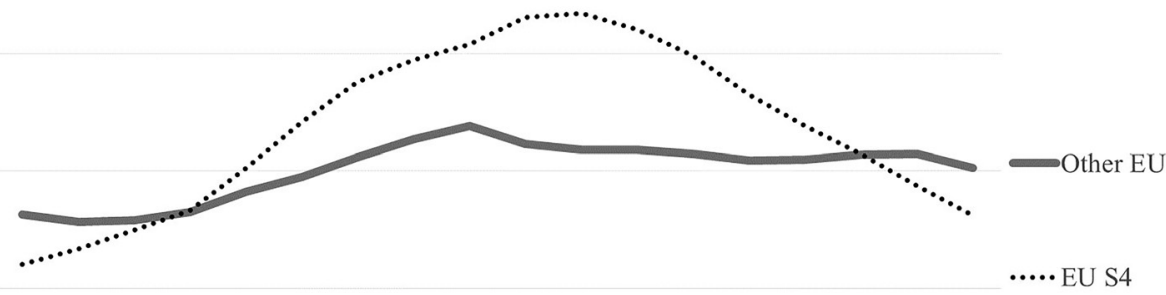

50

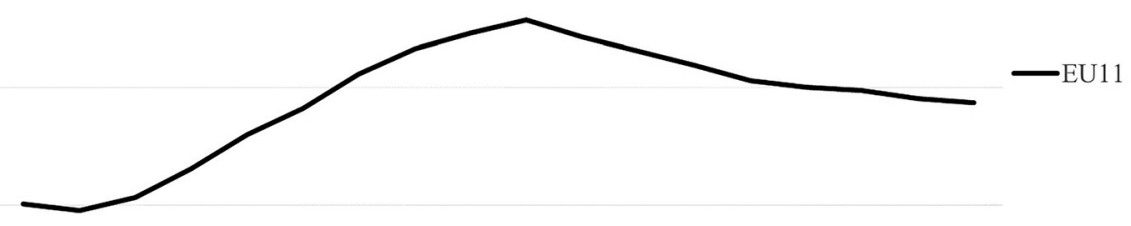

25 200120022003200420052006200720082009201020112012201320142015201620172018

Fig. 7. Current account imbalances and private credit in the EU, 2001-2018 Source: Calculations based on Eurostat.

Notes: For the definition of the country groups EU S4 and EU11, see the Notes to Fig. 2. 
More generally, the policy and institutional innovations at the European level that followed the previous crisis successfully addressed the root causes of the large nominal macroeconomic imbalances that led to the previous crisis. However, they did not address the root causes of poor overall institutional quality in some of the EU MSs. As Székely - Kuenzel (2021) argued, the EU did not manage to improve the institutional channel. This asymmetric progress resulted in the former nominal imbalances being transformed into real imbalances, a low-growth-low-investment path in the Southern European MSs.

However, this conflict is not an inherent one, it is present because of another wave of asymmetric development in the EU. Cross-border financial investment flows increased in importance throughout the world following the wave of capital account liberalization in the early 1990s. Such liberalization, like other forms of market integration, allows investors to optimize over a much larger set of investment opportunities. Hence, it offers a potential for improving allocative efficiency. However, to realize this potential fully, there is a need for flanking reforms to ensure that the macro prudential risks are properly addressed and that there is a matching improvement in the quality of financial (banking) intermediation within, both, the capital exporting and importing countries. This latter step was taken much later in the process when the consequences of an unbalanced development became painfully clear.

For the Sothern European countries to recover their investment ratio, and to import the necessary amount of capital, they and the EU as a whole need to restore the balance in their development paths. In the first place, the companies in Sothern Europe need to offer more investment opportunities that can be financed by outside companies. At present, the EU is the biggest exporter of savings in the world. Thus, there is no lack of funding within the Union, let alone globally. The long-prevailing low natural rate of interest in the global economy is a manifestation of an excess supply of savings. The fact that the fast-converging MSs that joined the EU after 2004 (EU11) could maintain a comfortable margin over the EU in their investment ratio also shows that the issue is not the lack of funds or the lack of the capacity of the financial system to intermediate in Europe.

\subsection{Presening social cohesion during a crisis}

Another major lesson of the previous crisis was the importance of maintaining social cohesion during and after a major crisis. As Fig. 8 indicates, the relative income level of a country within the EU greatly determines its capacity to support the most vulnerable, showing the implications of having no European-level social support schemes. The previous crisis temporarily weakened this capacity of the state throughout the EU. Thus, the regression curve for the EU shifted out somewhat. However, this negative impact of the crisis was much stronger in the hard-hit countries, which shows the failure of the Union to adequately support these countries during the crisis. However, even in those countries, most of the increase in the negative social impact can be attributed to the deteriorating income position.

As Fig. 8 shows, the resumption of sustained growth in Europe brought about a major improvement in the capacity of the state to support the most vulnerable in the EU, the stronger and more lasting the growth the more. The overall improvement in Europe helped even those countries that continued to experience a deterioration in their relative income position. 


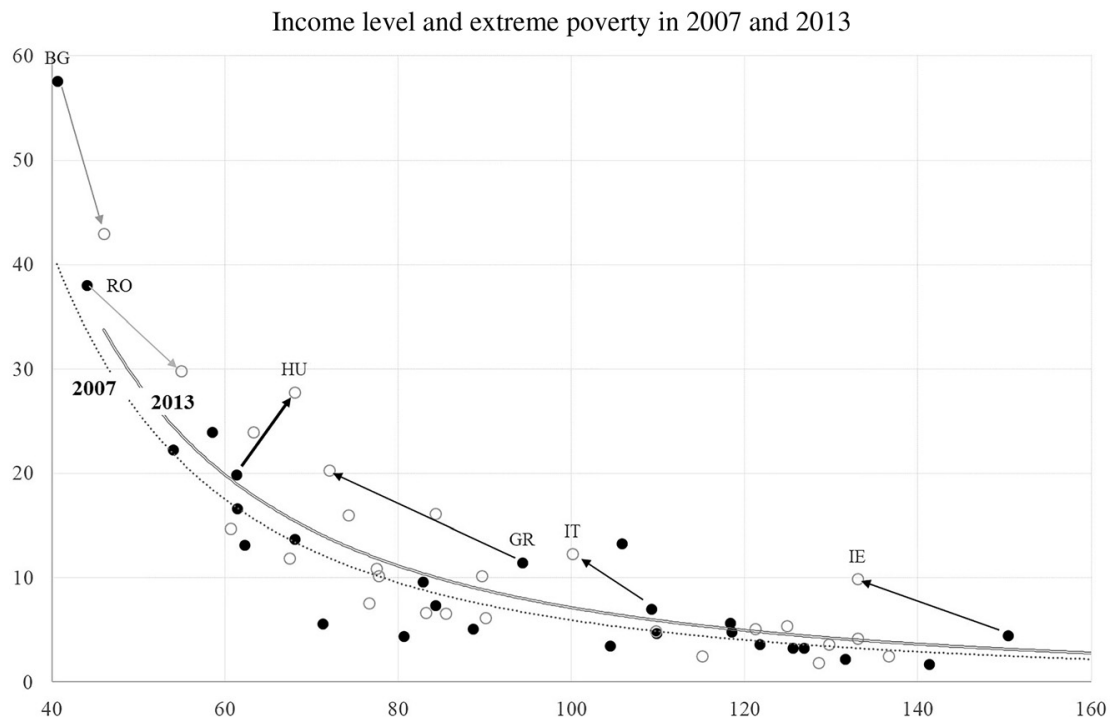

Income level and extreme poverty in 2013 and 2019

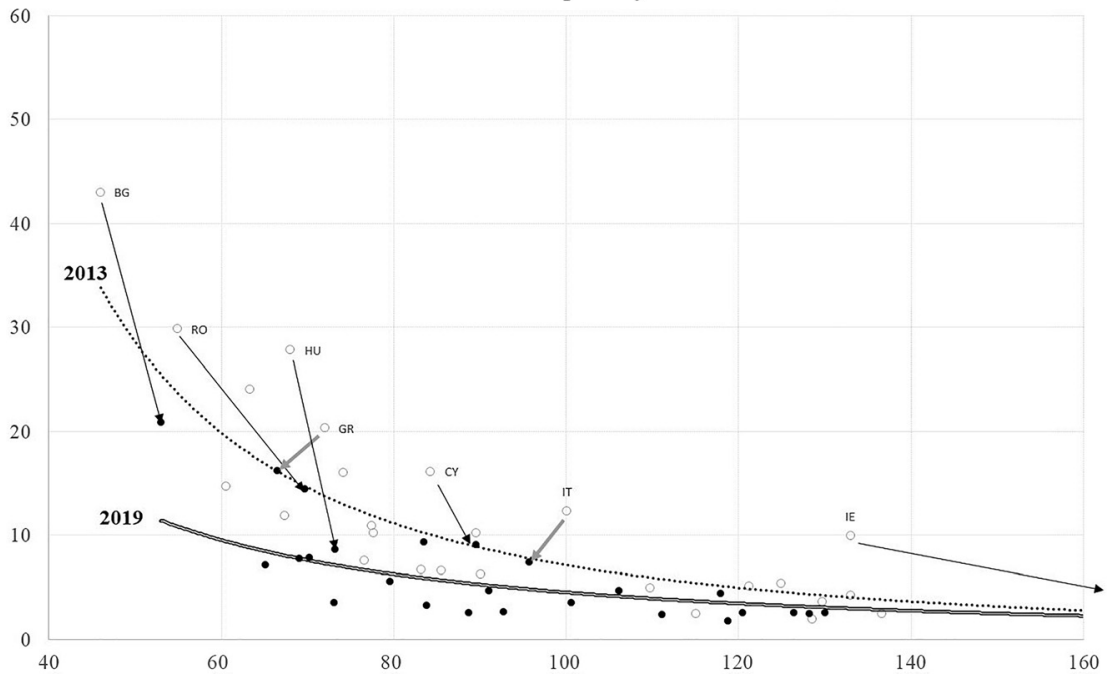

Fig. 8. Relative income level and the share of severely materially deprived people in the EU MSs in 2007-2013 and 2013-2019

Source: Calculations based on Eurostat.

Notes: On the horizontal axis, per capita income in purchasing power standard (PPS) relative to the average of the EU. On the vertical axis, the share of severely materially deprived people in the total population. Observations for individual EU MSs. Observations in the top figure for 2007 in dark grey, for 2013 white inside, and in the figure below, for 2013 white inside and for 2019 in dark grey. Arrows show the movement of a country in the indicated period. Trends are fitted power trends for the years indicated. 
Moreover, the continued strong convergence of the countries that joined the EU starting in 2004 flattened the European curve in a major way. ${ }^{2}$

To summarize, the lessons from the previous crisis were twofold. First, to help maintain social cohesion, it is important for the EU to find ways, as early as possible in the crisis, to enable the hard-hit MSs to extend their social support system to those most affected. As the social support system in the EU is almost entirely at the national level, this is a crucial aspect in the short run. Second, it is essential to rebuild the growth potential to lift people out of the poverty a major crisis almost inevitably causes in the hard-hit countries. The faster this is done, the faster the social performance improves. As we shall discuss below, flanking reforms are also important to reduce the pressure on the social system to correct market outcomes and to improve the efficiency of social expenditure. However, these reforms probably take even longer.

\subsection{The danger of losing the cutting edge of the EU}

The divergence of the Southern European MSs combined with the rapid convergence of the high-income countries of South East Asia posed a challenge to the former group of the EU MSs (Fig. 2). However, the Asia challenge for the EU is much broader and by now concerns the most developed and innovative part of the EU, too. In the past decade and a half, a group of new major global innovator countries has emerged, including South Korea, Taiwan, Singapore, China (Hong Kong and other developed parts such as Shanghai and Beijing), India and Israel.

As we mentioned earlier, in the golden age of the EU, the EU has also established itself as a major global player in innovation. However, as Fig. 9 shows, since the turn of the century, the high-income countries of South East Asia and the most developed parts of China have emerged as a new major innovator group rapidly catching up with the EU. Most of the decline in the share of the EU in US patents was at the cost of Germany and France, the two biggest global innovators of the EU. By 2015, Korea filed more patents in the US than Germany, compared with about one-third back in $2002 .^{3}$

The overall performance of the US and the EU was more or less the same in this period regarding the US patent filing. However, this meant that the US maintained its dominant position in innovation vis-à-vis the EU. Moreover, the cutting edge of the US, its most innovative states, such as California, broadly kept pace with the new emerging global innovators and pulled ahead of the major innovator countries of the EU (Fig. 9). ${ }^{4}$ The major smaller global innovator countries of the EU, such as the Netherlands, Sweden, Belgium, Denmark and Finland, as a group broadly kept pace with the overall trend, but not with Israel that has also emerged as a global innovator country.

\footnotetext{
${ }^{2}$ Hungary showed a rather different development, rapidly moving away from the curve for the EU but this was dominantly related to the national policies (introducing a flat personal income tax (PIT) and reforming the social support system), not the design of the financial assistance program. Nevertheless, despite major and widely debated issues surrounding the new approach, the resumption of rapid growth brought Hungary back to the European curve by 2019 .

${ }^{3}$ Japan, the other major global innovator outside the US, suffered a similar, perhaps even bigger loss in its share in the US patents.

${ }^{4}$ Most of the EU11 countries converged fast, but they are so small as innovators globally that their outstanding performance changed little in the overall trend for the EU as a whole. Recent research (Buti - Messori 2021) suggests that the trend of Asia getting ahead of the EU has continued, particularly in the area of ICT technologies.
} 

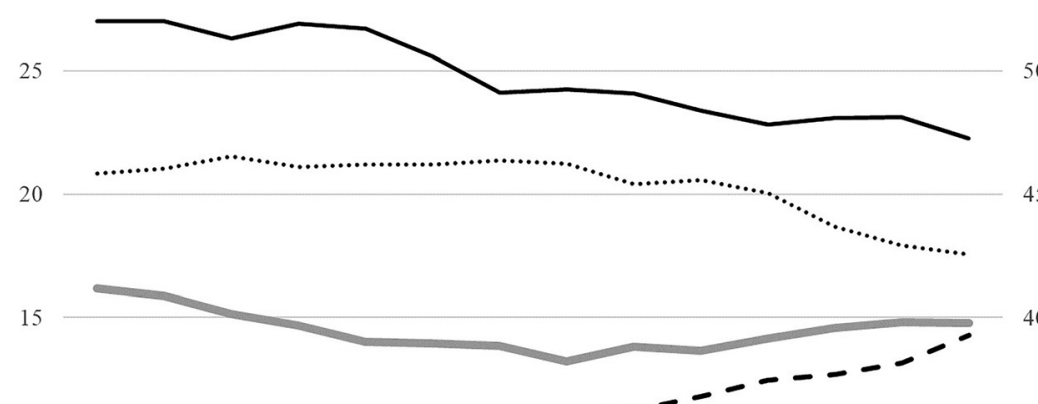

10

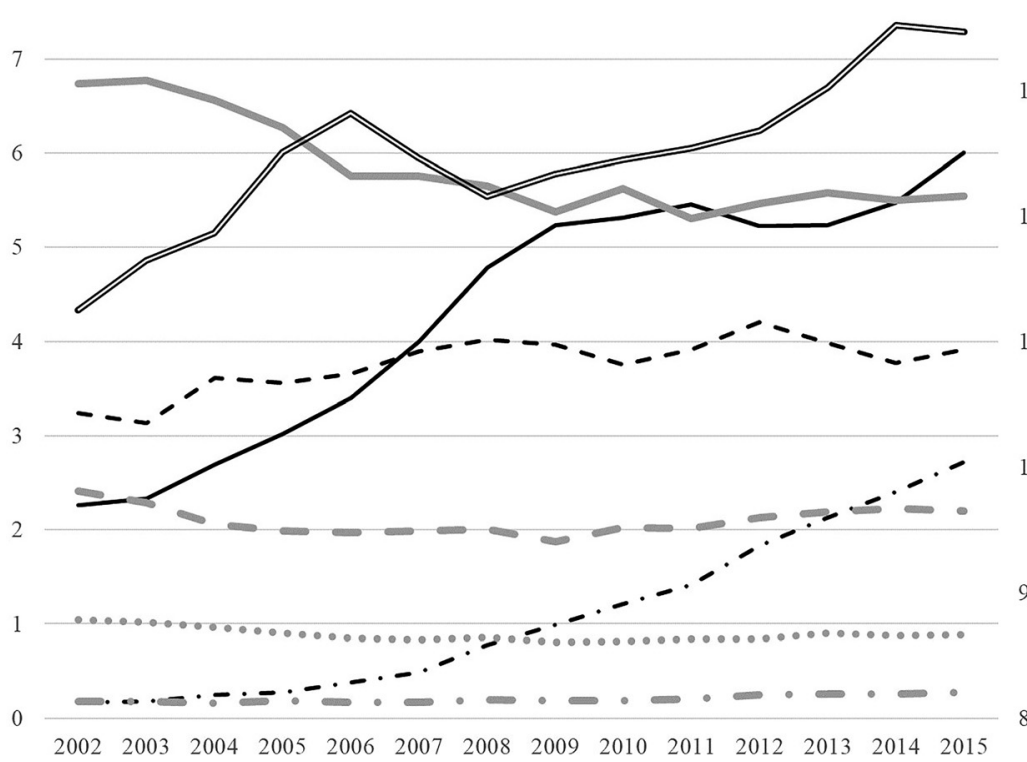

Fig. 9. Shares in US patents, 2002-2015

Source: Calculations based on data from the U.S. Patent and Trademark Office.

Notes: The group "Asia innovative" is the sum of the shares of China, Hong Kong and Taiwan, India, and Singapore. 


\section{THE COVID CRISIS: HOW TO ADDRESS THE NEW CHALLENGES AND STRENGTHEN THE EU?}

The COVID crisis hit the EU just a few months after the new European Commission took office in late 2019 with the twin transitions in the centre of its development strategy. The idea was to use the twin transitions as an opportunity to re-energize the economy and re-enforce the EU's role as a leading innovator in green technology. The equal emphasis on digital transition is central to the success of this strategy, as Europe has been left behind by the US and Asia in this area. Moreover, digitalization is essential to avoid a painful trade-off between greening (and greying) and growing. The only way out is accelerating innovation, particularly to speed up digitalization.

The challenge is made bigger by the fact that the twin transitions entail a major shift towards a knowledge-based and innovation-driven economy, which requires high-quality institutions and high-skill labour. However, the EU MSs, and regions within them are very unevenly endowed by these factors. Moreover, the success with accelerating innovation may bring about another difficult trade-off between growth and fairness.

\subsection{Lessons learned: policy and institutional innovation in the COVID-crisis}

The EU learned its lessons from the previous crisis (Buti 2020; Buti - Papacostantinou 2021). Policy and institutional innovations were fast and decisive when the COVID crisis hit the EU economy. The "Support to mitigate Unemployment Risks in an Emergency" (SURE) solidarity fund was set up and operationalized quickly, which allowed national social security systems to extend support to the most affected and vulnerable people to the fullest extent. The political agreement on the Next Generation EU was also reached fast. This component, particularly the Recovery and Resilience Facility (RRF) addresses many of the problems discussed above. It increases the overall size of the support from the EU budget significantly, albeit it is a one-off scheme not a new permanent feature of the budget system of the EU. It provides sizable investment funds to support public and private investment in the countries that have been most affected by the trend of divergence described above.

However, effective implementation of the Next Generation EU, particularly the RRF via credible and ambitious national Recovery and Resilience Programmes (RRPs) is a major challenge. Fig. 10 attempts to capture such political challenge by what one can term as "the Next Generation EU trilemma" (Buti - Polli 2021). Only reforms that are consistent with the gamechanging nature of the Next Generation EU would bring about the lasting changes. This implies the need to lengthen the time horizon of governments by carrying out investment projects and reforms which are consistent with the 'two Rs' of the RRF. To respond to the need for structural change and enjoy citizens' support, the programmes should help the economies recover after the COVID lockdowns and strengthen their fundamentals by making it more resilient to future shocks. Hence, countries need to commit to a time-bound implementation of well-identified growth-enhancing structural reforms, originating from several vintages of country-specific recommendations made in the European Semester. ${ }^{5}$

\footnotetext{
${ }^{5}$ The recently approved recovery and resilience plan for Italy demonstrates this point well (European Commission 2021). It contains a large number of major reforms previously identified in the European Semester as crucial for improving public and private institutions and enhancing the growth potential of the country.
} 


\section{Citizen support}

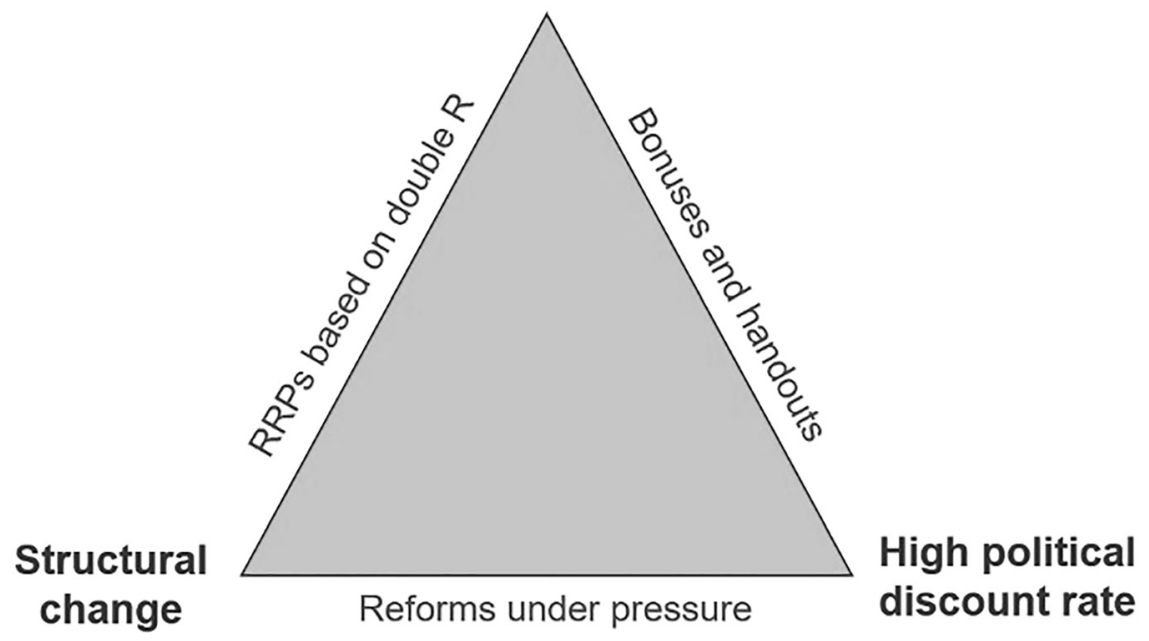

Fig. 10. The Next Generation EU trilemma

Source: Buti - Polli (2021).

Moreover, for the first time in the history of the EU, this is financed by joint borrowing at the EU level. This greatly reduces cost, promotes financial market stability, and ensures a supportive overall macroeconomic policy mix by creating more room for countercyclical fiscal policy. Unlike in the previous crisis, the fiscal stimulus goes to the countries that need it most as the allocation is developmental needs-based and the size of the fiscal stimulus that comes from the EU budget is rather large in those countries, despite the fact that the scheme overall is modest relative to the area-wide GDP (less than 1\%). Furthermore, the decisive political commitment to the Next Generation EU stabilized financial markets all across the EU. Thus, unlike in the previous crisis, borrowing costs remained rather stable throughout the EU and, thus, there is no pressure on the hard-hit countries to rain in fiscal support in a premature manner.

If successfully implemented, the Next Generation EU can help arrest the trend of divergence in Europe the previous crisis triggered by prompting the Southern European MSs to reverse the decline in the quality of their institutions, and by helping the EU11 countries to avoid creating such a negative trend in the first place. It can also give a boost to the twin transition in Europe, which in turn would provide a major market for those EU companies that produce innovation and technology for the twin transition.

\subsection{The role of institutions to preserve the cutting edge of the $\mathrm{EU}^{6}$}

It is well recognized in the literature that institutional quality is a major driver of development (North 1990; Acemoglu et al. 2005). As Fig. 11 shows, the impact is likely to be particularly

${ }^{6}$ This part builds on Buti - Székely (2021). 


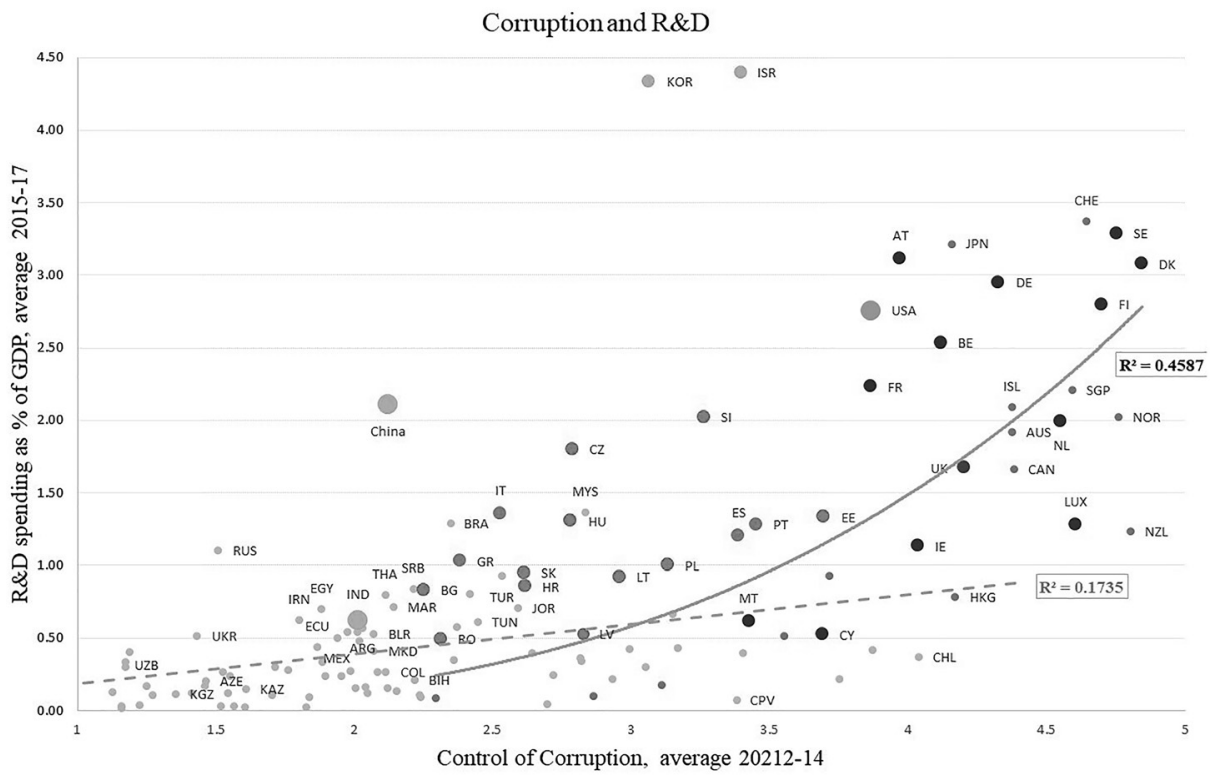

Rule of Law and R\&D

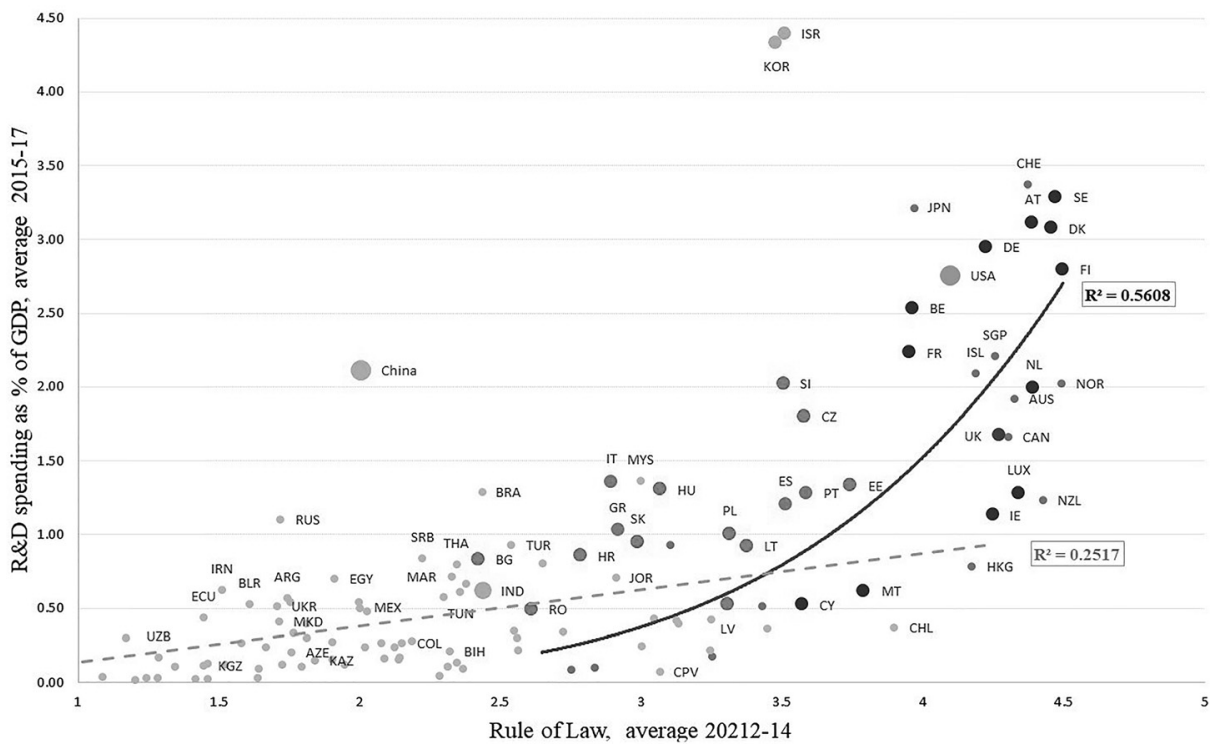

Fig. 11. Corruption control and rule of law and R\&D at different development levels Source: Székely (2020a).

Notes: Based on the corresponding WGI sub-indices, both calculated as averages for 2012-2014 and increased by 2.5 to make observations non-negative. Trend lines in grey are for the bottom four quintiles of the countries by per capita GDP in PPP, averaged for 2015-2017, observations in grey. Trend lines in dark grey are for the upper quintile countries, observations in dark grey. 
strong and work in a non-linear fashion as the knowledge-based and innovation-driven part of the economy becomes dominant. ${ }^{7}$

To demonstrate the nature of this relationship, we focus on two elements of institutional quality, the control of corruption and respect of the rule of law. Innovation is an inherently high-risk activity. Therefore, the companies engaging in innovation aim to locate such activity in constituencies where the additional risks emanating from weaknesses in corruption control and rule of law are minimized. Moreover, to recover the cost of innovation and produce a return that is commensurate with the risks involved, the legal protection of the intellectual property is essential so that innovation rent can be collected (Aghion et al. 2021). ${ }^{8}$

As these charts suggest, without a major improvement in institutional quality, it will be increasingly difficult for the Southern European countries to arrest the trend of lagging behind in innovation described earlier (Fig. 9), and for the EU11 countries to progress with their transition towards a knowledge-based and innovation-driven economy (Gattini et al. 2021). The accumulation of high-skill human capital will be equally important (Buti - Székely 2021).

\subsection{How to presenve cohesion?}

A major lesson of the previous crisis is that the social consequences of a crisis can be large, longlasting, particularly if there is a major divergence in economic performance among the countries and there is a group of countries that gets trapped into a low investment-low growth development path. Social security systems are entirely national in the EU and the EU budget has only a very small component to support the national social support systems. Therefore, the EU-level policy and institutional innovation could help in two areas to avoid the repetition of the experience of the previous crisis.

First, by removing the liquidity constraint on the social security systems (budgets) of the hard-hit countries. This has been achieved by setting up SURE. Second, by addressing the root causes of the trend of divergence that followed the previous crisis. The Next Generation EU, particularly the RRF is the main policy and institutional innovation that aims to help in this regard. If successfully implemented, it can limit or even reverse the previous trend of divergence, which in turn can reduce the pressure on the social security systems of the countries concerned.

Nevertheless, the extent of social inequality differs widely among the EU MSs, reflecting major differences in the overall level of development and in the capacity of the state to correct for inequality produced by the market outcomes (Székely 2020b). Regarding the degree of (disposable) income inequality at the lower end of the income distribution (the most vulnerable decile), the EU countries span almost the entire world distribution (Fig. 12). Some of the EU

\footnotetext{
${ }^{7}$ These charts show a correlation. Causality may well run in both directions, and there may be common causes driving both factors (quality of institution and innovation). Nevertheless, if institutional quality in a country deteriorates, like in the Southern European EU member states (Székely - Kuenzel 2021), this chart suggests that it is unlikely that such a country will be able to attract knowledge-based and innovation-driven activities and firms.

${ }^{8}$ The figure suggests that the nature of the relationship between the quality of institutions and the relative size of research and development in an economy is turning highly nonlinear as countries move towards knowledge-based, innovationdriven activities. This may well reflect the increasing importance of allocative efficiency as an economy approaches the frontier of economic development (Acemoglu et al. 2006). Many EU countries in Western and Northern Europe belong to this group, and several others in Southern and CEE have or are about to enter the transition towards this phase of development.
} 


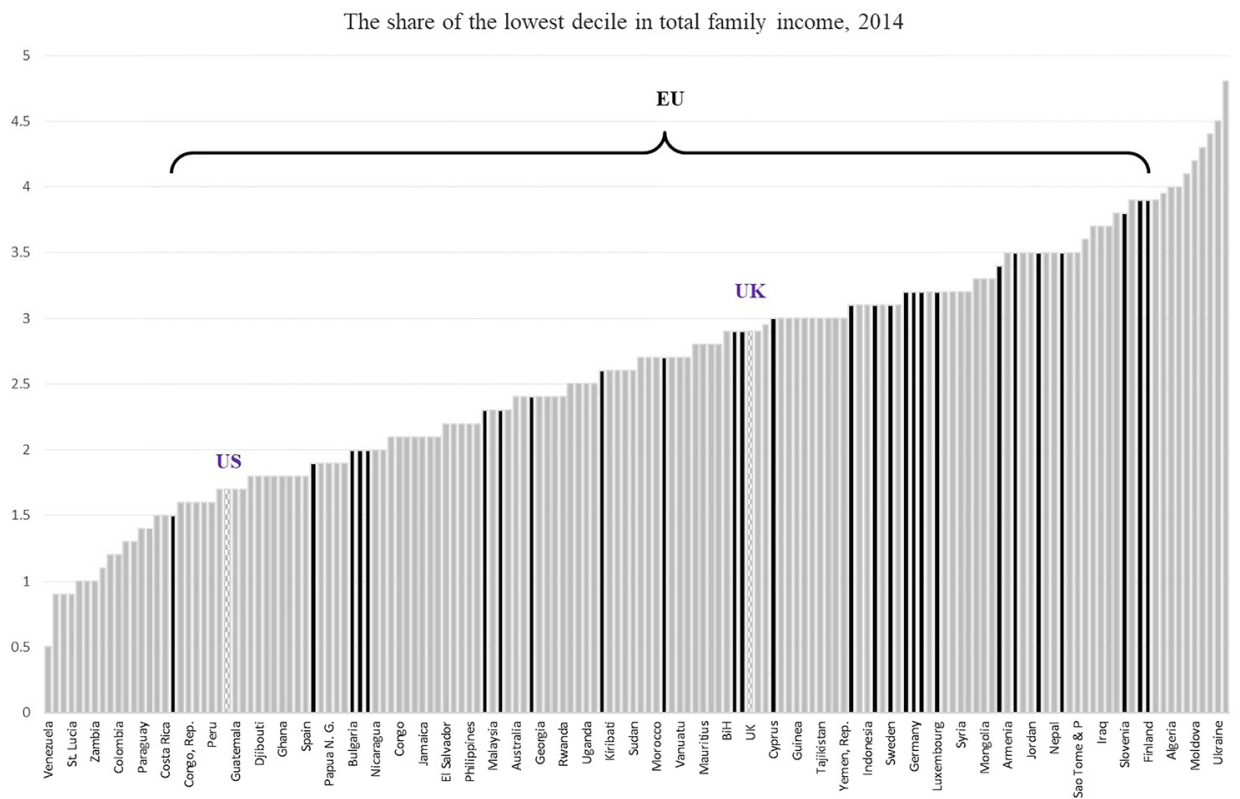

Fig. 12. Income shares of the families in the lowest decile of income distribution in total disposable family income in 2014

Source: Székely (2020b).

MSs (such as Slovenia, Czechia, Denmark, Finland, Sweden and Estonia) are among the countries which secure the highest (disposable) income share to the most vulnerable decile in the world, while some other MSs are among the countries that offer the lowest income shares in the world.

Nevertheless, the EU as a whole has a less unequal income distribution than the US (Fig. 13). This difference is a result of having different paths in the past half-century. Back in the late 1960s, the US had an income distribution rather similar to what the EU has today. If we look into the evolution of the US income distribution, it is the top 5 (or even top 1\%, see Aghion et al. 2021) that gained at the cost of the other groups.

The degree of inequality in a society is as much determined by market outcomes as it is by government policies. The major difference between the US and the western EU countries with large social expenditure, such as France, may not be mostly attributable to the differences in the extent to which government policies, redistribution through the budget modify market outcomes, but perhaps more to the differences in market outcomes (Bozio et al. 2020). If so, and if a move towards a more innovative economy brings about a higher innovation rent - a major factor behind the evolution of the US income distribution (Aghion et al. 2021) - there will be a need for the mitigating policies to avoid the highly-unequal market outcomes, which otherwise could be a result of successful twin transitions.

Within the EU, the share of government social expenditure in GDP varies greatly, and overall, it seems to have no correlation with the degree of social inequality defined broadly to 
60

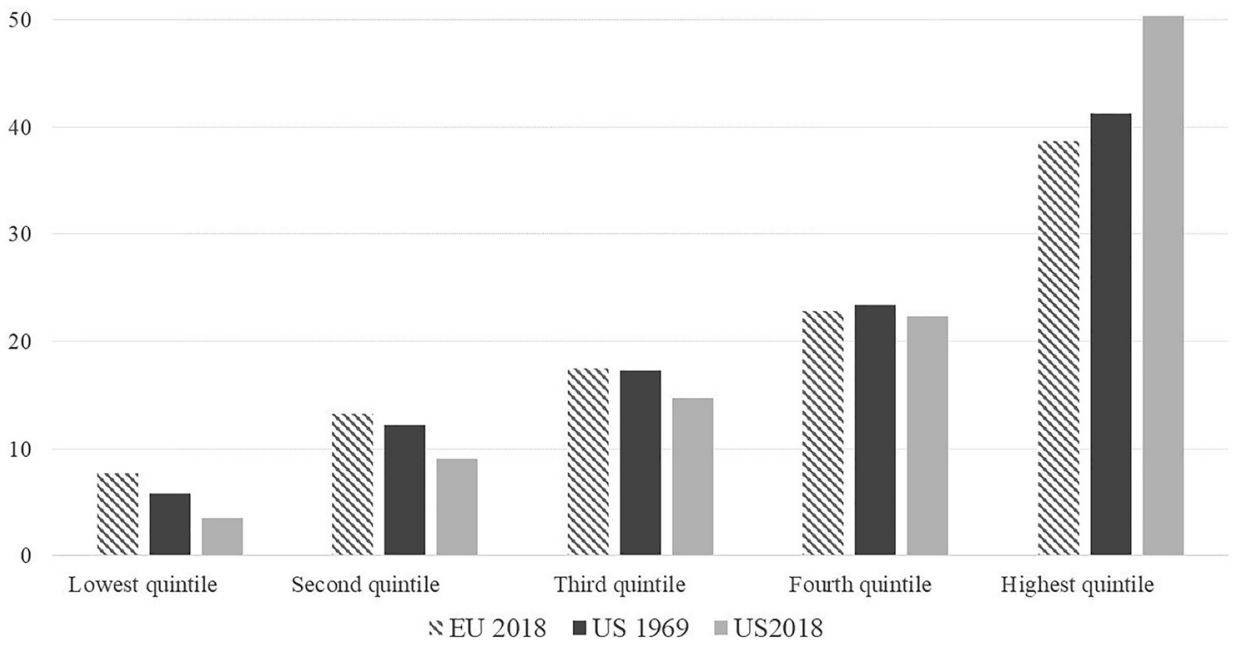

Fig. 13. Share in total income by quintiles in the EU in 2018 and in the US in 1969 and 2018 Source: Calculations based on data from Eurostat and US Census Bureau.

include income, education and health outcome (Fig. 14). However, if we look into this relationship for the different groups of the EU MSs we discussed above, we can nuance this finding and also link back this issue to our central theme, the quality of institutions. If we take the EU11, the Southern European, and the other MSs separately, the impact of social spending on inequality becomes very visible.

For each group separately, there seems to be a fairly steep relationship between social spending and inequality in a broader sense. Put differently, the return on higher social spending in terms of cohesion seems to be high, albeit different groups of countries seem to move along different curves. For example, the top social spenders in the EU11 group, which still spend less than the average in the EU, produce the lowest degree of inequality in the EU. In fact, Slovenia and Czechia are among the most equal societies in the world (Székely 2020b). The Southern European countries, on the other hand, devote around the same share of GDP to social expenditure but produce a higher degree of social inequality. For them to achieve a degree of inequality close to the rest, it seems they would have to devote a much higher share of their GDP to social spending.

An alternative and perhaps more feasible approach for all countries would be to improve the quality of existing public spending and to focus on policies that reduce the inequality that market outcomes produce, such as policies that make educational achievement better and more equal within society. This will be perhaps even more imperative when the twin transitions proceed and these countries move towards a more knowledge-intensive and innovation-driven economy. 


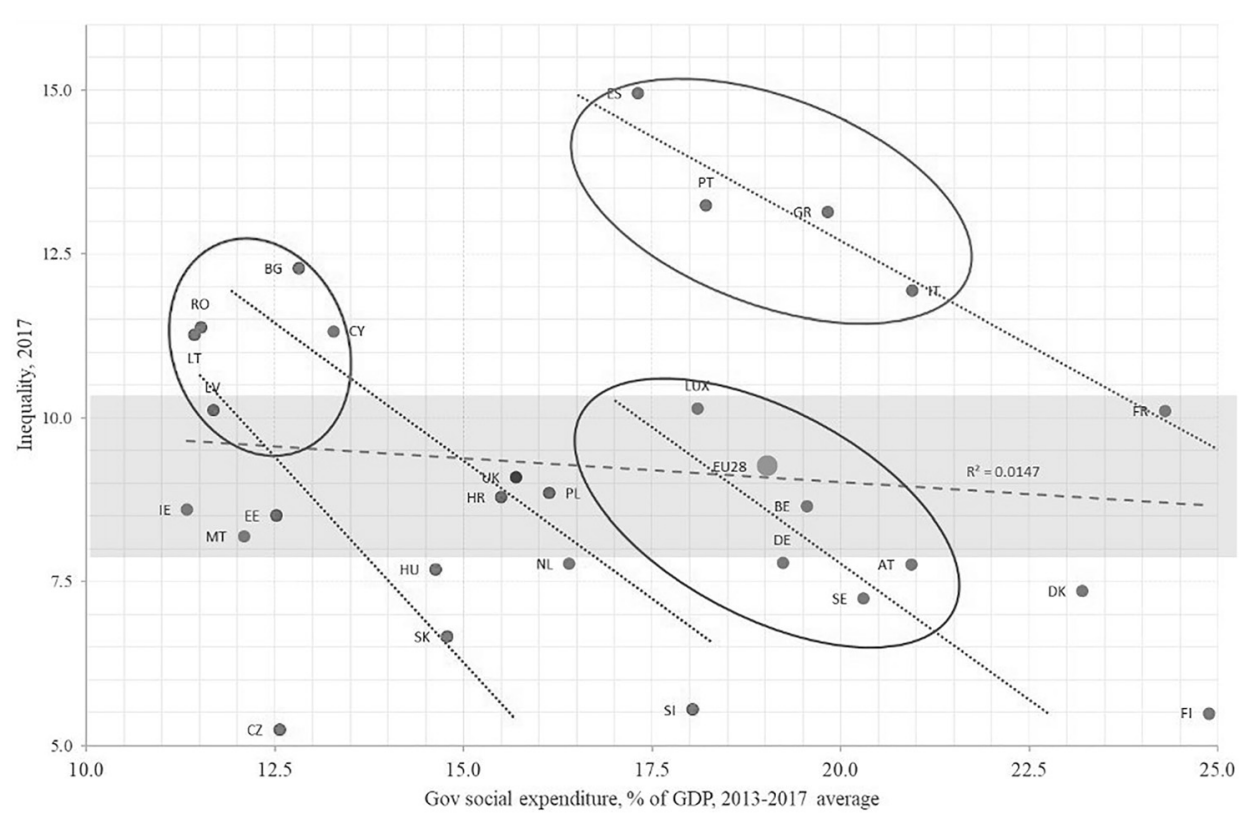

Fig. 14. Social expenditure and social inequality in the EU, 2017

Source: Eurostat for social expenditure, UNDP for social inequality.

Notes: Social inequality is measured by the UNDP indicator derived from the inequality-adjusted SDI calculations, which reflects inequality in income, educational achievement and life expectancy.

By putting the emphasis on major structural reforms, and making the funds available conditional on the implementation of these reforms, the Next Generation EU will most certainly help the MSs to be fit for a knowledge-based and innovation-driven economy. The reforms involved are wide-ranging and well-based in country surveillance (European Semester), thus are growth-enhancing. What will be important is to ensure that the flanking reforms that can mitigate any possible impact on social inequality are also pursued and that reform reversals are prevented. The danger of reform reversals is particularly high when domestic ownership of reforms fades and they can take several forms, some of which are harder to detect before they create major problems (Székely - Ward-Warmedinger 2018). ${ }^{9}$ Hence, further strengthening country surveillance, particularly to avoid an increase in social inequality will be essential.

\section{CONCLUSIONS: GETTING IT RIGHT THIS TIME AROUND}

A crisis tends to stress-test the economy, the society, and the state. It is particularly difficult to pass this stress test if a crisis happens soon after a previous major crisis. Moreover, the stress test of a crisis is more challenging for a relatively young institutional structure, such as the EU. This is what makes the COVID crisis so special in its history.

${ }^{9}$ For a more general discussion of the issue of external influence on domestic economic policies, see Aidt et al. (2021). 
The previous crisis left the EU with divergence, diminishing global position, and a threat to its cutting edge. This needs to be reversed. The EU needs to find ways to devise a policy response to the COVID crisis that not only fosters recovery in the short term but revitalizes the Union over the medium to long run. It needs to offer a new narrative. The twin transitions, to turn green and digital, have the potential to form the core of a new narrative for the EU. A narrative that focuses on the ways in which the EU can help its most developed MSs to remain at the global frontier of economic, social and institutional development and the others to converge to the global frontier as fast as possible. However, credible narratives are born out of success. The fate of the Lisbon goals is a stark reminder of the dangers of empty slogans. For the EU to be successful in promoting prosperity and cohesion, it needs to rebalance its development. This is the ultimate goal of Next Generation EU.

Every country, or union of countries, needs to have a sharp cutting edge of its economy. In today's world, this is the knowledge-based, innovation-driven part of the economy. Countries in which this part dominates the economy tend to be at the global frontier of economic, social and institutional development. The EU is well represented in this group, its most developed MSs are, and have been long, at the global frontier of development. Their public and private institutions are among the best in the world. This allowed them to benefit greatly from globalization and from the creation of the single market for goods in the EU. Their firms took a leading role in creating global value chains by investing abroad (outward FDI), dominantly in other EU countries. This way, they remained highly competitive globally and established the EU as a dominant player in the international trade of goods.

However, the EU entails countries belonging to two other major groups, the countries that are in the transition towards a knowledge-based and innovation-driven economy and the countries that are still to approach this transition. The most important tasks in this regard are to improve the working of the institutional channel and strengthen the cohesion of the Union. This requires policies and institutional reforms at the European level that help these countries to improve their public and private institutions and to reduce social inequality and bring the MSs more similar to each other in this regard. To make the twin transitions successful and lasting, social solidarity should be elevated from a national concept to a European one. Creating a more modern and equal Europe would offer a new narrative for the EU for the twenty-first century.

\section{ACKNOWLEDGEMENT}

The authors would like to thank Reinhard Felke, Alessio Terzi and Alessandro Turrini for helpful comments. Any remaining errors are the sole responsibility of the authors.

\section{REFERENCES}

Acemoglu, D. - Aghion, P. - Zilibotti, F. (2006): Distance to Frontier, Selection, and Economic Growth. Journal of the European Economic Association, 4(1): 37-74.

Acemoglu, D. - Johnson, S. - Robinson, J. A. (2005): Institutions as a Fundamental Cause of Growth. In: Aghion, P. - Durlauf, S. N. (eds): Handbook of Economic Growth. New York, NY: North-Holland, Vol. 1a, pp. 386-454. 
Aghion, P. - Antonin, C. - Bunel, S. (2021): The Power of Creative Destruction: Economic Upheaval and the Wealth of Nations. Harvard University Press.

Aidt, T. S. - Albornoz, F. - Hauk, E. (2021): Foreign Influence and Domestic Policy. Journal of Economic Literature, 59(2): 426-487.

Aksoy, C. - Eichengreen, B. - Saka, O. (2020): The Political Scar of Epidemics. NBER Working Paper, No. 27401. Bozio, A. - Garbinti, B. - Goupille-Lebret, J. - Guillot, M. - Piketty, T. (2020): Predistribution vs. Redistribution: Evidence from France and the U.S. CEPR Discussion Paper, No. 15415.

Buti, M. (2020): A Tale Two Crises: Lessons from the Financial Crisis to Prevent the Great Fragmentation. VoxEu.org (CEPR), 13 July 2020.

Buti, M. - Messori, M. (2021): Towards a New International Economic Governance: The Role of Europe. Mimeo, in preparation.

Buti, M. - Papacostantinou, G. (2021): The Legacy of the Pandemic: How COVID-19 is Reshaping Economic Policy in the EU. CEPR Policy Insights, No. 109.

Buti, M. - Polli, O. (2021): Veto Player Theory and the Governance of the Recovery and Resilience Facility. VoxEu.org (CEPR), 11 February 2021.

Buti, M. - Székely, I. P. (2021): Building-Back-Better After the COVID Crisis in Europe: The Twin Transition and Cohesion. SUERF Policy Note, No. 234.

Buti, M. - Turrini, A. (2015): Three Waves of Convergence. Can Eurozone Countries Start Growing Together Again? VoxEu.org (CEPR), 17 April 2015.

European Commission (2021): Annex to the Proposal for a Council Implementing Decision on the Approval of the Assessment of the Recovery and Resilience Plan for Italy. SWD (2021) 165.

Gattini, L. - Gereben, Á. - Kollár, M. - Revoltella, D. - Wruuck, P. (2021): Towards a New Growth Model in CESEE: Three Challenges Ahead. In: Landesmann, M. - Székely, I. P. (eds): Does EU Membership Facilitate Convergence? The Experience of the EU's Eastern Enlargement. Palgrave-Macmillan, Vol. I, pp. 91-122.

Lane, P. R. (2021): The Resilience of the Euro. Journal of Economic Perspectives, 35(2): 3-22.

North, D. C. (1990): Institutions, Institutional Change, and Economic Performance. New York: Cambridge University Press.

Seiler, P. (2021): Firms' Investment Decisions in Response to the COVID-19 Pandemic: Causal Evidence from Switzerland. CEPR COVID Economics, 73, 23 March 2021, pp. 81-136.

Székely, I. P. (2020a): The Knowledge Channel and the EU. Fairness, University of Colorado, Boulder, CEUCE, May 2020, Mimeo.

Székely, I. P. (2020b): The Super Dimensions of Development and the EU. Fairness, University of Colorado Boulder, CEUCE, May 2020, Mimeo.

Székely, I. P. - Kuenzel, R. (2021): Convergence of the EU Member States in Central-Eastern and South Eastern Europe: A Framework for Convergence Inside a Close Regional Cooperation. In: Landesmann, M. - Székely, I. P. (eds): Does EU Membership Facilitate Convergence? The Experience of the EU's Eastern Enlargement. Palgrave-Macmillan, Vol. I, pp. 27-87.

Székely, I. P. - Ward-Warmedinger, M. (2018): Reform Reversals: Areas, Circumstances and Motivations. Association of Comperative Economic Studies, 60(4): 559-582.

van den Noord, P. - Székely, I. P. (eds) (2011): Economic Crisis in Europe: Causes, Consequences and Responses. London: Routledge.

Open Access. This is an open-access article distributed under the terms of the Creative Commons Attribution 4.0 International License (https://creativecommons.org/licenses/by/4.0/), which permits unrestricted use, distribution, and reproduction in any medium, provided the original author and source are credited, a link to the CC License is provided, and changes - if any - are indicated. (SID_1) 